To the Editors:

\title{
Characteristics of victims of alleged child sexual abuse referred to a child guidance clinic of a children's hospital
}

\author{
Y M Rohanachandra, D M A Dahanayake, P A S Pathigoda, G S Wijetunge \\ (Index words: child sexual abuse, psychological consequences, offender characteristics) \\ Ceylon Medical Journal 2015; 60: 163-164
}

Child sexual abuse (CSA) is a major public health problem affecting all cultures and social classes. Estimated global prevalence of CSA is $11.8 \%$ [1]. Retrospective studies in Sri Lanka have shown prevalence of sexual abuse among adolescents to be $21.9 \%$ [2]

A retrospective descriptive study was carried out of all children referred through courts or Judicial Medical Officer to a Child Guidance Clinic at Lady Ridgeway Hospital, from 2010-2014, due to alleged CSA. Psychological consequences were assessed by a Consultant Psychiatrist and diagnosis was made according to the International Classification of Diseases, $10^{\text {th }}$ edition. Approval was obtained from Ethics Review Committee of The Lady Ridgeway Hospital, Colombo. Data obtained from case records were suitably altered to maintain confidentiality.

Thirty-five children presented with alleged CSA, during 2010-2015, with the highest number referred in 2013(Table 1). Majority (57.1\%) were females. Commonest age group was $12-14$ years $(9 / 35)$. Sixty percent were from Colombo District. In 9 (25\%), parents were separated. In $5(14 \%)$ the mother was abroad. In all cases, the perpetrator was male. Majority 29 (83\%) were known to the child. In most (29/35), a single perpetrator was involved. In $23(66 \%)$, abuse occurred on several occasions by the same person. Threats or violence was used in 17 (49\%) and rewards were given in $7(20 \%)$. The commonest form of sexual abuse was non-penetrative contact 17 (49\%). Co-existing forms of abuse were present in $13(37 \%)$. Psychological consequences were present in $24(68 \%)$, with post-traumatic stress disorder being the commonest 7 (20\%).

Globally, CSA is commoner in females [1], which is compatible with our findings. Similarly, highest rates of CSA has been reported among adolescents [3]. Mother
Table 1. Characteristics related to sexual abuse

\begin{tabular}{|c|c|}
\hline & Number \\
\hline \multicolumn{2}{|c|}{ Relationship to the perpetrator } \\
\hline Neighbour & 7 \\
\hline Father & 6 \\
\hline Uncle & 4 \\
\hline Teacher & 2 \\
\hline Older child & 2 \\
\hline Stranger & 6 \\
\hline Unknown & 9 \\
\hline \multicolumn{2}{|l|}{ Type of abuse } \\
\hline Contact non penetrative & 17 \\
\hline Genital penetrative & 8 \\
\hline Anal penetrative & 6 \\
\hline Oral penetrative & 3 \\
\hline Non contact & 1 \\
\hline \multicolumn{2}{|c|}{ Place where abuse occurred } \\
\hline At the childs' home & 15 \\
\hline At the perpetrators' home & 11 \\
\hline \multicolumn{2}{|c|}{ Psychological consequences } \\
\hline None & 11 \\
\hline PTSD & 7 \\
\hline Adjustment reaction & 6 \\
\hline Sexualized behaviour & 5 \\
\hline Anxiety disorder & 3 \\
\hline Adjustment disorder & 2 \\
\hline Depression & 1 \\
\hline
\end{tabular}

Psychiatry Unit, Lady Ridgeway Hospital, Colombo, Sri Lanka.

Correspondence: YMR, e-mail: <yasodha_mk@yahoo.com>. Received 18 June and revised version accepted 25 July 2015. 
living abroad has been shown to be a risk factor, which is supported by the present results [2].

Worldwide, majority of abusers are male and known to victims [3]. In the current study, all perpetrators were male and $83 \%$ were known to the child. However, a previous Sri Lankan study showed most perpetrators to be strangers [4]. Data from Australia has shown that commonest place of abuse was at offender's home [5]. However, in our study, most abuse occurred at child's home $(43 \%)$. Literature shows that perpetrators gain compliance of children by "grooming behaviour", rather than by threats [5]. In contrast, in the current study, threats or violence has been used in $17(48.6 \%)$ with rewards being given only in $20 \%$.

Previous community studies of adolescent boys in Sri Lanka showed oral and intra-crural sex to be the commonest forms, with $10.7 \%$ being penetrative sex [2]. Percentage of anal penetrative sex in boys was higher $(17.1 \%)$ in the present study, possibly due to differences in sampling. Previous literature has reported that different forms of child abuse and neglect frequently co-exist [3]. This was supported by our results.

In previous studies psychological consequences have been reported in up to two-thirds of victims, this was consistent with our results [3]. Previous data show that post-traumatic stress disorder (PTSD) was present in $48 \%$ [3]. In our study, rate of PTSD was lower (20\%). The most likely reason is that our data included findings at the first visit following abuse and PTSD may develop up to six months after the initial abuse.

The sample was derived from referrals to child guidance clinic and may not represent all children subjected to CSA as only some make complaints and are referred for assessment. This is a limitation of our study.
Since a majority of perpetrators were known to victims, public education programmes should aim at recognition of the danger that exists at home in addition to danger from strangers. Since CSA frequently coexists with other forms of abuse, clinicians should be vigilant about this. All children should be screened for psychological problems following abuse in order to minimise adverse outcomes, as majority show psychological consequences.

\section{Conflicts of interests}

There are no conflicts of interest.

\section{References}

1. Stoltenborgh M, Ijzendoorn MHV, Euser EM, et al. A global perspective on child sexual abuse: Meta-analysis of prevalence around the world. Child Maltreat 2011; 16: $79-101$.

2. Abeywardene ASA, Atukorale SH, Abeynayaka KKDCC, et al. A study on knowledge and prevalence of sexual harassment and abuse among schoolboys in Colombo District. Sri Lanka J Child Health 2004; 33: 9-17.

3. Glaser D. Child sexual abuse. In: Rutter M, Bishop D, Pine D, Scott S. eds. Rutter's child and adolescent psychiatry. $5^{\text {th }}$ ed. London: Wiley-Blackwell, 2010: 440-59.

4. Dias T, Kociejowski A, Rathnayake S, et al. Sexual violence against women: a challenge. Ceylon Med J 2014; 59: 107-8.

5. Smallbone SW, Wortley RK. Child Sexual Abuse: Offender Characteristics and Modus Operandi: Trends and Issues in Crime and Criminal Justice. Australian Institute of Criminology. Report number: 193, 2001. 